\title{
"The Nominees for Best Article ...": Awards for the Most Valuable Papers on Psychotherapy in 2018
}

\author{
James C. Overholser ${ }^{1}$ (D) \\ Published online: 8 June 2019 \\ (c) Springer Science+Business Media, LLC, part of Springer Nature 2019
}

\begin{abstract}
Each year, many important articles are published that make valuable contributions to the field of psychotherapy. It is helpful to remain informed about recent developments in the field, and respect the useful refinements that are being proposed in various journal articles. Unfortunately, with so many journals in the field, it can be challenging to find the best articles, and some important papers may be overlooked. In recent years, the situation has become even worse with the expansion of many new and often predatory journals, publishing inferior papers. The Journal of Contemporary Psychotherapy awards program has two main goals. First, the review of the recent literature helps to highlight the useful papers published during the previous year. Second, the awards program helps to praise the best and inspire the rest, aiming to motivate the field to publish high quality papers. The awards selection process involved a review of numerous academic articles published during 2018 in 60 different professional journals. Then, a panel of judges reviewed 52 finalists for ten possible awards. Adequate agreement was found to provide awards for nine different categories of research studies or review articles. Each winning paper is reviewed, and most authors provide a behind-the-scenes look at the work involved in their valuable contribution to the field of psychotherapy.
\end{abstract}

Keywords Psychotherapy $\cdot$ Publication $\cdot$ Peer review

Each year, a tremendous amount of work goes into every journal article publication. In order to reach publication status, most journal articles require a massive amount of time, effort, and dedication from the research participants, the research assistants, the graduate students and faculty members, the authors, reviewers, and journal editors. The Journal of Contemporary Psychotherapy continues with its awards program, striving to highlight the best articles published during the previous year. Despite the incredibly helpful articles that are hereby nominated for an award, there is a risk that some strong articles could get lost amidst the myriad of publications, especially now with the expansion of predatory journals in the field.

In March of 2019, active members of the editorial board were asked to submit nominations for entries in any of the award categories, but they could not nominate their own

James C. Overholser

overholser@case.edu

1 Department of Psychology, Case Western Reserve

University, 10900 Euclid Avenue, Cleveland,

OH 44106-7123, USA work, their colleagues, or their current or former students. They were encouraged to nominate papers that were published in any scholarly journal. Furthermore, in an effort to remain informed and unbiased, the JCP editorial staff reviewed numerous journal articles published during 2018 in the following 60 journals: Acta Psychiatrica Scandinavica, Addictive Behaviors, American Journal of Orthopsychiatry, American Journal of Psychiatry, American Journal of Psychotherapy, American Psychologist, Annual Review of Clinical Psychology, Assessment, Behavior Research and Therapy, Behavior Therapy, Clinical Psychology Review, Clinical Psychology: Science and Practice, Cognitive and Behavioral Practice, Cognitive Therapy and Research, Comprehensive Psychiatry, Counselling and Psychotherapy Research, Counselling Psychology Quarterly, Counselling Psychology Review, Ethics and Behavior, International Journal of Cognitive Therapy, International Journal of Eating Disorders, International Journal of Psychology and Counseling, International Journal of Psychiatry in Medicine, International Journal of Psychiatry in Clinical Practice, JAMA Psychiatry, Journal of Abnormal Psychology, Journal of Affective Disorders, Journal of Autism and 
Developmental Disorders, Journal of Attention Disorders, Journal of Behavior Therapy and Experimental Psychiatry, Journal of Clinical Psychiatry, Journal of Clinical Psychology, Journal of Clinical Psychology in Medical Settings, Journal of Clinical Child Psychology, Journal of Consulting and Clinical Psychology, Journal of Contemporary Psychotherapy, Journal of Counseling Psychology, Journal of Humanistic Counseling, Journal of Humanistic Psychology, Journal of Marital and Family Therapy, Journal of Mental Health Counseling, Journal of Nervous and Mental Disease, Journal of Personality Assessment, Journal of Psychotherapy Integration, Journal of Rational-Emotive and Cognitive-Behavioral Therapy, Personality and Individual Differences, Personality Disorders: Theory, Research, and Treatment, Professional Psychology, Psychiatric Clinics of North America, Psychoanalytic Inquiry, Psychoanalytic Psychotherapy, Psychoanalytic Psychology, Psychological Assessment, Psychological Bulletin, Psychological Medicine, Psychotherapy, Psychotherapy Research, the Clinical Supervisor, the Counseling Psychologist, and Training and Education in Professional Psychology. Additional articles that had been published in other journals were included in the review, identified through a supplemental search for each award category. The massive list of publications was then narrowed down to 109 articles. Then, the editor-in-chief narrowed the list down to the final four articles deemed best to represent each of the award categories.

When reviewing the recent literature, eligible articles included case studies, cross-sectional assessment research, longitudinal designs, treatment-outcome studies, systematic review papers, opinion-based editorials, and meta-analysis reports. Articles could examine psychotherapy with children, adolescents, or adults. The clinical services could be provided to medical patients, psychiatric inpatients or outpatients. The treatment could be provided through individual psychotherapy, couples therapy, family-based approaches, or group therapy sessions. However, studies that focused on pharmacological treatments were excluded. Furthermore, articles co-authored by former award winners were excluded as well as articles published by members or colleagues of the journal's editorial board.

During the process of literature review and article selection, several additional criteria were used to identify the finalists. First, the article should have a solid foundation in research, whether as a specific empirical investigation or as a comprehensive review paper, forming conclusions that are based on well-controlled research. Thus, a research study relied on appropriate samples, established measures, and proper statistical analyses. All studies adhered to established ethical guidelines. Second, the conclusions should be based on adequate samples, whether examining the number of participants that were evaluated in a research study, or the number of articles that were reviewed as part of a review paper.
However, the article must focus on problems experiences by medical patients or psychiatric patients. Papers were excluded if they relied on samples of convenience (e.g., college student volunteers, anonymous online surveys). Third, any statistical results should derive from appropriate analytic procedures, whether examining differences between groups or associations among measures. Fourth, the article should have direct relevance to clinical practice, with conclusions and recommendations that appear useful for the front-lines clinician. Articles that relied on methodology that does not align with common clinical activities (e.g., computerized assessments or online surveys) were excluded. Fifth, the topic should have broad appeal, regardless of theoretical orientation or stage of career, avoiding articles that might be interesting but focused on a narrow topic that is only relevant to specialists in that area. Sixth, the article appears to be well written, and enjoyable to read. These criteria set a high standard, and might be useful goals when colleagues begin the task of writing their own manuscript. Furthermore, these criteria aim to encourage a true integration of science as practice. The scientist-practitioner model is difficult to accomplish (Overholser 2010), but provides an important guide for professional development (Overholser 2007).

A panel of experts (three members of the JCP editorial board) helped to rank order the best papers from the list of nominees. The nominated papers and the criteria for ten awards were distributed to the panel of experts to be used as a rough guide for their rank ordering of papers in each category. Unfortunately, no agreement could be reached on one award category and was dropped from the current review. For the final nine categories, each award category was reviewed with four nominated papers.

\section{Most Valuable Contribution to Assessment, Diagnosis, or Case conceptualization}

Assessment, diagnosis, and case conceptualization lay the foundation for understanding each client and initiating a plan for treatment. This award recognizes the important advances in research or theory that can help clinicians to better understand and treat mental health problems. Eligible articles focused on clinical issues that were examined in medical patients or psychiatric patients, and the findings were relevant to understanding or treating people with mental health concerns. Review papers were eligible if they appeared to advance the use of current psychiatric diagnostic strategies, psychological assessment tools, or clinical case conceptualization. Research studies were eligible if their participants include medical or psychiatric patients, but were excluded if they relied on college student subjects, online surveys, or mTurk methodology. The nominees are: 
Boals, A. (2018). Trauma in the eye of the beholder: Objective and subjective definitions of trauma. Journal of Psychotherapy Integration, 28 (1), 77-89.

Davies, A. (2018). From disorder to challenge: Using lifespan developmental theories to reframe distress. Counselling Psychology Review, 33 (1), 24

Johnstone, L. (2018). Psychological formulation as an alternative to psychiatric diagnosis. Journal of Humanistic Psychology, 58 (1), 30-46.

Philippot, P., and colleagues. (2018). Case conceptualization from a process-based and modular perspective: Rationale and application to mood and anxiety disorders. Clinical Psychology and Psychotherapy, 26, 175-190.

And the winner is .... Pierre Philippot and colleagues (2018) for their insightful article on case conceptualization. The article presents a transdiagnostic model that retains a strong focus on psychological processes to guide the understanding of each client. To protect the process of psychotherapy, the article highlights various psychological domains that are central to mental health and treatment strategies. In this age that emphasizes biological factors and medical treatments, Philipott's article helps to keep psychologists focused on the mind and mental processes. The author states (Pierre Philippot, personal communication, May 6, 2018) "this paper stems from a long lasting collaboration with colleagues from two French universities and one of my former graduate student. Our ultimate aim is to develop a processbased modular intervention for anxiety and mood disorder. The awarded paper reports our work on the first step of this protocol, the case conceptualization module. Beyond the reflection on case conceptualization, the conception of this module also necessitated the validation of several questionnaires. It was first implemented and tested in the consulting center of our psychology department. In a second step, it was implemented in a general hospital in Paris, and disseminated among private practitioners. We are now collaborating with about 170 psychotherapists who are using our case conceptualization module and providing us with valuable feedback. The module is freely accessible on the Internet (www.uclep .be/process). The paper was fertilized with much field experience and feedbacks. The publishing of the paper was a long process. A very important question raised pertains to the validity of relying on questionnaires to assess psychological processes that are by nature dynamic, and several of which are implicit and not directly accessible to consciousness. Another important issue concerns the benefits of tailor-made therapy, in contrast to standardized therapy. Indeed, the empirical evidences are still inconclusive in this respect. We are presently working on another module of this process-based modular protocol. This "self-help" module aims at providing patients with essential information regarding how everyday behavior impacts upon mood and anxiety.
It addresses issues such as emotion regulation, sleep, eating, or exercise. It comprises quizzes, tips, clinical vignettes, and self-evaluation."

\section{Most Valuable Contribution to Psychotherapy Theory}

The best treatment strategies are often based on a strong theoretical foundation. Unfortunately, the current emphasis on evidence-based practice encourages clinicians to become technicians who closely follow a treatment manual (Shedler 2018). Theory is sometimes replaced with a pure focus on empirical support that can become disconnected from broader theory. The field of psychotherapy is guided by several useful theories, and the conduct within psychotherapy sessions benefits from useful and validated theories. This award highlights important contributions toward the theoretical foundation necessary for effective psychological treatments, emphasizing the value of a useful theory to guide clinical practice. Eligible articles could provide a novel theoretical view, a systematic review of the published literature, or an empirical study that explores the theoretical foundations of an established theory. The nominees are:

David, D., and colleagues. (2018). 50 years of rationalemotive and cognitive-behavioral therapy: A systematic review and meta-analysis. Journal of Clinical Psychology, 74, 304-318.

Magill, M., and colleagues. (2018). A meta-analysis of Motivational Interviewing process: Technical, relational, and conditional process models of change. Journal of Consulting and Clinical Psychology, 86 (2), 140-157.

Bowins, B. (2018). The rational unconscious: Implications for mental illness and psychotherapy. American Journal of Psychotherapy, 71 (1), 28-38.

Gazzillo, F., and colleagues. (2018). The components of psychoanalysis: Factor analyses of process measures of 27 fully recorded psychoanalyses. Psychoanalytic Psychology, 35 (2), 184-195.

And the winner is .... Francesco Gazillo and colleagues (2018), who examined 540 recorded sessions from psychoanalytic therapy that had been conducted with 27 clients. The investigation revealed several key factors that appear centrally involved in the therapist's view and the client's experience over the course of therapy. The research highlighted the value of therapy discussions that enhance client awareness of emotions, and address patient defenses. The authors state (Francesco Gazzillo, personal communication, May 6, 2018): "this paper is the result of an effort of a group of clinicians and researchers coordinated by me and working at the Department of Dynamic and Clinical 
Psychology, "Sapienza" University of Rome, and a group of clinicians and researchers from the Psychoanalytic Research Consortium (New York) coordinated by Sherwood Waldron. Our aim was to explore from a bottom up perspective which are the components of a psychoanalytic treatment and which of these components affect the outcome of psychotherapy. This research has been possible thanks to the effort of ten people who dedicated almost 5 years to the multi-instrumental assessment of 540 sessions of psychoanalysis. It is based on the idea that psychoanalysis needs empirical research to change and grow so that it could meet the needs of our patients and the standard of science."

\section{Most Valuable Contribution to Psychotherapy Process}

Across all forms of psychotherapy, effective work relies on a strong alliance between therapist and client. As noted many years ago, "Without a good therapeutic relationship, any procedure will fail; with it, with most patients, probably any procedure will succeed" (Frank, in Brady et al. 1980, p. 288). Unfortunately, there is a risk that the power of the therapeutic relationship may be neglected or its impact is being minimized in the age of short-term therapy and manualized approaches to treatment. It seems that most publications about psychotherapy emphasize the impact of the approach as measured by treatment-outcome research, while the subtle nuances that are laced throughout the process of psychotherapy become minimized, neglected, or lost. This award aims to highlight the central importance of psychotherapy process and the experiential relationship factors that are central to successful psychotherapy. Eligible papers reviewed the literature of conducted research on psychiatric patients and their experience during psychotherapy sessions. The nominees are:

Lavik, K., and colleagues. (2018). The first sessions of psychotherapy: A qualitative meta-analysis of alliance formation processes. Journal of Psychotherapy Integration, 28 (3), 348-366.

Farber, B., Suzuki, J., \& Lynch, D. (2018). Positive regard and psychotherapy outcome: A meta-analytic review. Psychotherapy, 55 (4), 411-423.

Kolden, G., and colleagues. (2018). Congruence/genuineness: A meta-analysis. Psychotherapy, 55 (4), 424-433.

Cameron, S., Rodgers, J., \& Dagnan, D. (2018). The relationship between the therapeutic alliance and clinical outcomes in cognitive-behavior therapy for adults with depression: A meta-analytic review. Clinical Psychology and Psychotherapy, 25, 446-456.
And the winner is .... Kristina Lavik and colleagues (2018) for their meta-analysis of the first sessions of psychotherapy. This meta-analysis examines the process of alliance building from the perspective of both the therapist and the client. The article includes many useful guidelines that can help to guide the establishment of a sound working alliance, especially showing a genuine desire to understand the struggles of each client, and helping clients to feel respected and understood. The authors confront the issue of "balancing what you do, with who you are" (Lavik et al. 2018, p. 360). The article includes many recommendations that are useful for the novice therapist as well as the seasoned clinician. According to Kristina Osland Lavik (personal communication, May 25, 2019): "Back when I was a student in clinical psychology, I was taught how the therapeutic alliance was vital for successful psychotherapy outcomes. However, I experienced practical guidelines offering clinical perspectives on how to promote constructive alliance establishment as scarce when progressing into clinical work. Later, I encountered my current supervisor Professor Christian Moltu, who suggested studying the development phases of therapeutic alliances in natural settings in a research project. This particular meta-analysis is the first step in describing important relational processes that occur in the early therapeutic encounter. The meta-analysis summarizes and re-analyzes qualitative studies on the formation of the early therapeutic alliance from both the therapist and the client perspective. From this groundwork, we are currently conducting the empirical part of project, employing Interpersonal Process Recall interviews through the five first sessions of psychotherapy in ordinary clinical settings. We hope that the insights resulting from this project will be helpful for clinicians and aid in supporting constructive alliance work."

\section{Most Valuable Contribution with Enduring Value}

Everyone is familiar with the oft quoted warning: "Those who cannot remember the past are doomed to repeat it" (George Santayana, 1905, The Life of Reason). Throughout the history of psychotherapy, there have been many many valuable papers that have provided useful insights into psychological processed. It remains important to understand and respect the ideas that had been described long ago by some of the pioneers in the field, especially in those papers most likely to be neglected-journal articles that were published at least 50 years ago. The nominees are:

Jones, M.C. (1924). A laboratory study of fear: The case of Peter. Pedogogical Seminary and Journal of Genetic Psychology, 31, 308-315. 
Shakow, D. (1945). Training in clinical psychology: A note on trends. Journal of Consulting Psychology, 240242.

Rosenzweig, S. (1936). Some implicit common factors in diverse methods of psychotherapy. American Journal of Orthopsychiatry, 6 (3), 412-415.

Rogers, C.R. (1957). The necessary and sufficient conditions of therapeutic personality change. Journal of Counseling Psychology, 21, 95-103.

And the winner is .... Carl Rogers (1957) for his seminal contribution to the field of psychotherapy. In this paper, Rogers (1957) confronts the necessary and sufficient conditions for effective psychotherapy. Rogers admits the most "startling feature" of his view is the requirement that these six conditions are both necessary and sufficient for all forms of psychotherapy. Many people might admit these conditions are necessary, but it becomes much harder to argue they are sufficient for effective personality change. Throughout the article, Rogers relies on his personal experience as a psychotherapist, something this is often lost in contemporary articles. Furthermore, Rogers brings a soft argumentative style to his controversial proposal. Nonetheless, this article clearly highlights the value of empathy, congruence, and positive regard as central qualities in all forms of psychotherapy.

\section{Most Valuable Paper on Innovations in Psychotherapy}

The field of psychotherapy moves forward through the proposal of new ideas. However, it can be difficult to make broad proposals that are wildly innovative. Instead, innovations usually move forward one small step at a time. It is rare to see truly innovative work because journals are likely to reject papers that appear overly creative because they lack sound research to support their innovation. Thus, a conundrum slows the path of creativity. The award aims to encourage creative thinking and novel approaches that could help to redefine approaches to the treatment of mental health concerns. Each of the nominated papers presents some exciting and novel advances to the field of psychotherapy. The nominees are:

Muran, J.C., Safran, J., Eubanks, C., \& Gorman, B. (2018). The effect of Alliance-Focused Training on a cognitive-behavioral therapy for personality disorders. Journal of Consulting and Clinical Psychology, 86 (4), 384-397.

Hayes, S., \& Hofmann, S. (2018). A psychological model of the use of psychological intervention science: Seven rules for making a difference. Clinical Psychology: Science and Practice, 25, e12259.
Juarascio, A., and colleagues. (2018). Just-in-time adaptive interventions: A novel approach for enhancing skill utilization and acquisition in cognitive behavioral therapy for eating disorders. International Journal of Eating Disorders, 51, 826-830.

Pennebaker, J. (2018). Expressive writing in psychological science. Perspectives on Psychological Science, 13 (2), 226-229.

And the winner is ..... Chris Muran, Jeremy Safran, Catherine Eubanks, and Bernard Gorman (2018) for their impressive research on Alliance-Focused Training provided to 40 trainee therapists. In a well-controlled study, patients with diagnosed personality disorders were provided with or without Alliance-Focused training. The methodology used one of the most ethically sound approaches to control group research, and the study highlights the value of protecting the therapeutic relationship. The research emphasized the value of self-exploration and experiential learning as important tools in psychotherapy. The authors state (Chris Muran, personal communication, May 12, 2018) "This study represents a culmination of a longstanding concerted effort to go beyond showing the alliance is an important variable in many psychotherapies, even beyond our own efforts to study rupture repair as a change process -to train therapist abilities to build alliances and to negotiate ruptures -with the ultimate aim to redress psychotherapy failure rates. Of course, it could not be accomplished without the help of so many at Beth Israel Medical Center (now part of Mount Sinai), who were the infrastructure of our research program there since 1990."

\section{Most Valuable Contribution from a Specific Study on Psychotherapy}

The field moves forward one step at a time. Research is a slow process. Research with psychiatric patients is complicated, and research on psychological treatments is arguably the most challenging form or research in any area within the area of psychology. Each individual study is like a brick in a wall, whereby individual bricks are neglected until a full project has been constructed. Nonetheless, each brick serves an important role but often goes neglected for its strength and value. The award for contribution from a specific study hopes to highlight the unique insights and valuable findings gained from a specific research study conducted with mental health professionals or psychiatric patients in a clinical setting. Nominees are:

Celik, C., \& Odaci, H. (2018). Psycho-educational group intervention based on Reality Therapy to cope with aca- 
demic procrastination. Journal of Rational-Emotive and Cognitive Behavioral Therapy, 36, 220-233.

Mancke, F. and colleagues. (2018). Assessing the marks of change: How psychotherapy alters the brain structure in women with borderline personality disorder. Journal of Psychiatry and Neuroscience, 43 (3), 171-181.

Pinto-Coelho, K., and colleagues. (2018). When in doubt, sit quietly: A qualitative investigation of experienced therapists' perceptions of self-disclosure. Journal of Counseling Psychology, 65 (4), 440-452.

Maric, M., vanSteensel, F., \& Bogels, S. (2018). Parental involvement in CBT for anxiety-disordered youth revisited. Journal of Attention Disorders, 22 (5), 506-514.

And the winner is .... Kristen Pinto-Coelho et al. (2018) for their qualitative evaluation of psychotherapist self-disclosure. The article concludes that therapist self-disclosure can be effective when the therapist remains closely attuned to the client's situation, both interpersonal and intrapsychic. The researchers conducted detailed interviews with 19 experienced licensed psychologists who were currently working providing individual psychotherapy sessions. The consensus across these seasoned therapists showed therapist self-disclosure could be helpful when the therapist proceeded with thoughtful caution. It can be useful to instruct novice therapists that everything in session should be done for therapeutic purposes, and the therapist should avoid from responding as if involved in a casual conversation with a friend. Whenever considering therapist self-disclosure, it is wise to anticipate and evaluate the likely impact on the client. The article provides a thorough review of the issues, as revealed through these qualitative interviews. The authors state (Kristen Pinto-Coelho, personal communication, May 8, 2018): "Therapist self-disclosure may be beneficial or harmful to the client and the therapeutic relationship. To help therapists decide whether or not to disclose and to enhance understanding of how to disclose therapeutically, we qualitatively examined disclosures used by experienced therapists in psychotherapy. Successful and unsuccessful disclosures had similar antecedents, intentions, and content, but consequences differed (deepening the work vs. premature termination). These findings highlight the difficulty of disclosing therapeutically and the need for additional research. The more I study disclosure the less inclined I am to use it. That said, I have disclosed to tremendous therapeutic effect that would not have been possible using any other intervention."

\section{Most Valuable Contribution to Professional Development, Training or Supervision}

The future of psychotherapy lies in the hands of the next generation, and professional develop is key to enhancing their career path. In so many ways, the future of psychotherapy lies in the next generation of therapists. Graduate education, professional training, and clinical supervision are the keys to protecting the future psychotherapists. The award recognizes the important insights gained from a research study or review paper, helping to advance some aspect of professional development. Eligible papers confront important aspects of graduate training, clinical supervision, or career development that can help the trainees at the start of their careers or protect the careers of established professionals. The nominees are:

Mann, S., \& Merced, M. (2018). Preparing for entrylevel practice in supervision. Professional Psychology: Research and Practice, 49 (1), 98-106.

Mangione, L., and colleagues. (2018). Mentoring in clinical psychology programs: Broadening and deepening. Training and Education in Clinical Psychology, 12 (1), 4-13.

Theriault, A., \& Gazzola, N. (2018). Dilemmas that undermine supervisor confidence. Counselling and Psychotherapy Research, 18 (1), 14-25.

Sciberras, A., \& Pilkington, L. (2018). The lived experience of psychologists working in mental health services: An exhausting and exasperating journey. Professional Psychology: Research and Practice, 49 (2), 151-158.

And the winner is .... Lorraine Mangione and colleagues (2018) for their insightful survey of mentoring practices in graduate training programs in clinical psychology. The results highlight the preferred mentoring practices and includes recommendations that can help to improve the mentorship experience, with strong recommendations for protecting the supportive bond and personal connection that develops between trainee and mentor. The results encourage mentors to focus on the person of the trainee, focus on identifying and working toward major career goals, and building the confidence in the young psychologists. The authors state (Lorraine Mangione, personal communication, May 7, 2018): "This mentoring project was both a challenge and a joy! The challenge was that we wanted to include so much because we know the importance of mentoring: qualitative responses and quantitative answers, PhD and PsyD students and graduates, and participants representing different types of diversity especially ethnic/racial and gender. The joy was in the collaborative nature of our work: having student perspectives and unique vantage points involved at every stage allowed for mentoring within a project on mentoring, with faculty also learning from students. Given that a major finding was the importance of relationship in mentoring, the research process was embedded in a relational framework." 


\section{Most Valuable Contribution to Group Psychotherapy}

Each year, the awards program focuses on advances in a specific type of intervention or a specific psychiatric disorder to highlight. This year, group therapy is being highlighted. When conducting group psychotherapy sessions, a wide mix of ideas and strategies become relevant that may extend beyond the confines of traditional individual therapy sessions. Today, there is a risk that researchers or insurance companies will place excessive emphasis on short-term treatments, organized around a structured treatment manual, with a dominant focus on psychoeducational approaches that neglect the power of groups seen in process variables and group dynamics. To counter these pressures, it seems important to identify and highlight some of the unique aspects of group dynamics that enhance group therapy as a unique intervention that complements individual psychotherapy sessions. The nominees are:

Burlingame, G., McClendon, D., \& Yang, C. (2018). Cohesion in group therapy: A meta-analysis. Psychotherapy, 55 (4), 384-398.

Tavares, L., \& Barbosa, M. (2018). Efficacy of group psychotherapy for geriatric depression: A systematic review. Archives of Gerontology and Geriatrics, 78, 71-80.

Lesczc, M. (2018). The evidence-based group psychotherapist. Psychoanalytic Inquiry, 18 (4), 285-298.

Marziliano, A., and colleagues. (2018). Measuring cohesion and self-disclosure in psychotherapy groups for patients with advanced cancer: An analysis of the psychometric properties of the Group Therapy Experience Scale. International Journal of Group Psychotherapy, 68, 407-427.

And the winner is .... Gary Burlingame and colleagues (2018) for their meta-analytic review of group therapy cohesion. The article includes a thorough review of the group therapy literature, and a meta-analysis of 55 published research studies. The article concludes that cohesion among the group members is significantly associated with improvement from the therapy group. This finding holds across psychiatric diagnosis, treatment setting (i.e., inpatient or outpatient), or the theoretical orientation of the leader. The conclusion is clear; group leaders are encouraged to emphasize supportive relevant among the group members. The authors state (Gary Burlingame, personal communication, May 8, 2018): This meta-analysis came out of BYU's Consortium for Group Research and Practice-CGRP (http://cgrp.byu.edu) that is made up of faculty and students from 2 APA approve Ph.D. programs and a dozen undergraduate student research assistants. C-GRP focuses on identifying efficacious group treatments for different clinical populations and real-time measurement of group processes and outcomes to improve group outcomes.

\section{Most Valuable Contribution to the General Field of Psychotherapy}

Throughout 2018, there have been many interesting papers published on psychological treatments or related topics. The awards committee did not want to neglect some useful publications on interesting topics. This award category can cover a wide spectrum of topics that may or may not align with any of the other award categories, but nonetheless seem capable of providing readers with valuable insights into the field of psychotherapy. The award recognizes the value found in a published article that appears relevant to the general field of psychotherapy. The article shows potential for widespread utility and broad applications for the profession. The nominees are:

Wright, S., and colleagues. (2018). Wisdom at the end of life: Hospice patients' reflections on the meaning of life and death. Counselling Psychology Quarterly, 31 (2), 162-185

Bird, T., Tarsia, M., \& Schwannauer, M. (2018). Interpersonal styles in major and chronic depression: A systematic review and meta-analysis. Journal of Affective Disorders, 239, 93-101.

Meichenbaum, D., \& Lilienfeld, S. (2018). How to spot hype in the field of psychotherapy: A 19-item checklist. Professional Psychology: Research and Practice, 49 (1), 22-30.

Campos, R., Holden, R., \& Santos, S. (2018). Exposure to suicide in the family: Suicide risk and psychache in individuals who have lost a family member to suicide. Journal of Clinical Psychology, 74, 407-417.

And the winner is Don Meichenbaum and Scott Lilienfeld (2018) for their unique report on hype in the field of psychotherapy. This paper holds special acclaim, in this age of weak treatments and holistic healers. University instructors are likely to have many opportunities to educate the public about evidence-based practice and the value of research to support psychological treatments. When teaching a psychology course, students often ask questions about some of the novel approaches, and they often rely on unchecked internet sources to support their notions. The 19-item psychotherapy hype checklist can be distributed to help novices to explore the rational and empirical foundation of any approach to treatment. Although designed to confront psychological treatments, most of the items seem to apply quite well to 
medical interventions. The overarching goal is to encourage healthy self-doubt when confronted with innovations in the field of psychotherapy. The article helps readers to identify inflated claims that might be found in research reports or promotional materials, such as exaggerated advertisement claims and inflated job titles. The checklist should be of great value to consumers as well as mental health professionals. "The authors (Meichenbaum and Lilienfeld, personal communication, May 8, 2019) have long felt disturbed, dismayed, and disheartened by the continued proliferation of psychotherapeutic interventions marked by exaggerated claims of efficacy and that offer the promise of "quick fixes." Furthermore, we have frequently witnessed even the best and brightest of our colleagues and students embracing, advocating, and conducting non-evidence-based and theoretically questionable forms of psychotherapy. Our article, which drew upon a variety of formal (e.g., academic publications) and informal (e.g., websites) sources, was borne largely out of a desire to inform clinicians and clinicians-in-training of "warning signs" that often point to overhyped therapeutic interventions. We very much hope that it will prove useful to consumers of psychotherapy as well."

\section{Conclusions}

Throughout the past year, there have been many helpful articles published across a spectrum of academic journals. I am highly respectful the work of colleagues published by these esteemed colleagues. In addition to the nominees listed in this awards article, there have been many other useful publications that help to improve and advance the field the field of psychotherapy. Several categories were difficult to judge, because at least one other article showed great potential for advancing the field of psychotherapy.

The awards program aims to praise the best works in the field, and inspire the rest to push harder for solid articles that advance the field of psychotherapy. However, it can be easy to become critical of many articles that rely on weak methodology or have lost their focus on important psychological issues. I hope the awards process helps to encourage the field to create valuable articles about psychotherapy. The Journal of Contemporary Psychotherapy aims to publish articles that retain a strong and clear relevance to clinical work, confronts important issues related to the mind and mental processes of psychiatric patients, and collects data using clinical samples. The Journal tries to focus on papers that have broad appeal, explore an interesting topic or rely on an interesting methodology. For the awards program, the best papers address important topics so that even if the topic seems outside of a person's area of specialization, they would make time to read the paper, as it could enhance their general knowledge or be helpful in their teaching.
In contemporary practice, many quality papers rely on systematic reviews and meta-analysis. These procedures are helpful but a persuasive argument can also be addressed in a traditional review. Ideally, all nominated articles cover material that readers look forward to reading, the reader is likely to learn something useful, and instructors may assign for one of their graduate courses. Some strong and useful papers did not fit neatly into the award categories. For example, Wright et al. (2018) summarized useful advice that was shared by 15 terminally ill hospice patients. These patients expressed their views about life, death, meaning, and values. A qualitative analysis revealed important themes across the life views expressed in the semi-structured interviews.

Several recent articles have highlighted the importance of psychotherapy process variables and the beneficial impact of a strong therapeutic relationship (e.g., Farber et al. 2018; Fluckiger et al. 2018). These articles help to document the research support for well-known psychotherapy process issues, such as positive regard for the client (Farber et al. 2018), mutuality in session (Cornelius-White et al. 2018), client insight (Jennissen et al. 2018), and therapist genuineness (Kolden et al. 2018). Although these core process variables were emphasized many years ago, recent research has documented their impact of treatment outcome.

In conclusion, the awards program aims to highlight the best articles published during the past year. The overarching goal is to praise the best and inspire the rest, hoping to encourage researchers, authors, reviewers, and editors to publish quality papers that will protect and improve the field of psychotherapy. Hopefully, psychotherapy will continue to grow and expand as a strong and vibrant field.

\section{Editorial Postscript}

As editor-in-chief, I have many people to thank for their support and efforts during the past year. First, let me thank my panel of expert judges who evaluated the nominated papers and submitted their rank order preferences. I want to be especially respectful of one of my judges, Ed Watkins, whose publications were eligible again this year, but he was denied nomination because of his valuable manuscript that won an award last year. I want to thank the Long Island Consultation Center and Springer Publishers for the ongoing support for the journal and allowing me the professional freedom to steer the journal as I see fit. I am highly appreciative of my editorial board and ad hoc reviewers who have provided valuable feedback about many different submissions this past year. During the past 12 months, the following professionals have served as ad hoc reviewer: Steven Abell, Behrooz Afshari, Oladayo Ayobami Afolabi, Haifa Mohammed Saleh Al Gahtani, Shlomo Ariel, Ally Baier, Catherine Barber, Luz Bascunan, Denise Ben-Porath, Ray Bergner, Rachna Bhargava, Katja Boersma, Kelsey Bonfis, Gina Brelsford, Janet 
Brody, Fatima Bukhari, Kerry Cannity, Eduard Carratala, Charles Cedarberg, Aureliano Crameri, Rachel Crook-Lyon, Antonia Csillik, Luanne Davis, Gustavo Dionisio, John Donohue, Chris Eckhardt, Bruno Faustino, Espen Folmo, Julian Ford, Celeste Foster, Haruo Fujino, Valerie Gaus, Erica Gergely, Peter Gerhardt, Marv Goldfried, J. Grant, Huw Green, Eugena Griffin, Volkan Gulum, Jay Hamm, Duwad Harris, Marco Antonio Hartmann, Silvia Hernandez, Thomas Hoffman, Lara Honos-Webb, Isaac Hooley, Jurgen Hoyer, Felix Inchausti, Cary Jordan, Syed Muhammad Sajjad Kabir, Ebrahim Rahbar Karbasdehi, Aaron Kindsvatter, Nancy Kocovski, Ioanna Kousteni, Leonard Kratzer, Valerie Krupnik, Jeffrey Kuentzel, Michael Lasher, Tania Lecomte, Lloyd Leland, Maxwell Levis, Duane Lundervold, Jason Luoma, Dan Marques, Sarah Meinikoff, Shlomo Mendlovic, Matthew Mercer, Brian Miller, Sheelah Mills, Dawn Moeller, Laura Moesender, Elonora Natalini, Randy Nobbitt, John O'Connor, Bill O'Donohue, Isabelle Ong, Cynthia Osborn, Giovanni Ottoboni, Christophe Panichelli, Amanda Pearl, Tracy Prout, Amy Przeworski, George Rajesh, Anna Robinson, Lauren Rogers-Siran, Diego Romaiolli, Chiara Ruini, Deborah Serani, Thomas Skovholt, Douglas Snyder, Anders Sorensen, Ladislav Timulak, Tom Tomaszewski, Patricia McCarthy Veach, Abe Wolf, Paul Wong, and Jim Yokley. Clearly, the quality of papers that are being published in the Journal of Contemporary Psychotherapy is enhanced by the effort and dedication of many different professionals.

\section{Compliance with Ethical Standards}

Conflict of interest The author also serves as journal editor, but there is no conflict of interest.

Research Involving in Human and Animal Rights This is an editorial review paper and it did not involve human participants and/or animals.
Informed Consent Thus informed consent does not apply to this work.

\section{References}

Brady, J. P., Davison, G., Dewald, P., Egan, G., Fadiman, J., Frank, J. D., et al. (1980). Some views on effective principles of psychotherapy. Cognitive Therapy \& Research, 4, 271-306.

Cornelius-White, J., Kanamori, Y., Murphy, D., \& Tickle, E. (2018). Mutuality in psychotherapy: A meta-analysis and meta-synthesis. Journal of Psychotherapy Integration, 28(4), 489-504.

Farber, B., Suzuki, J., \& Lynch, D. (2018). Positive regard and psychotherapy outcome: A meta-analytic review. Psychotherapy, 55(4), 411-423.

Fluckiger, C., DelRe, A., Wampold, B., \& Horvath, A. (2018). The alliance in adult psychotherapy: A meta-analytic synthesis. Psychotherapy, 55(4), 316-340.

Jennissen, S., Huber, J., Ehrenthal, J., Schauenberg, H., \& Dinger, U. (2018). Association between insight and outcome of psychotherapy: Systematic review and meta-analysis. American Journal of Psychiatry, 175(10), 961-969.

Kolden, G., Wang, C., Austin, S., Chang, Y., \& Klein, M. (2018). Congruence/genuineness: A meta-analysis. Psychotherapy, 55(4), 424-433.

Overholser, J. C. (2007). The Boulder model in academia: Struggling to integrate the science and practice of psychology. Journal of Contemporary Psychotherapy, 37, 205-211.

Overholser, J. C. (2010). Ten criteria to qualify as a scientist-practitioner in clinical psychology: An immodest proposal for objective standards. Journal of Contemporary Psychotherapy, 40, 51-59.

Shedler, J. (2018). Where is the evidence for "Evidence-Based" Therapy? Psychiatric Clinics of North America, 41, 319-329.

Wright, S., Breier, J., Depner, R., Grant, P., \& Lodi-Smith, J. (2018). Wisdom at the end of life: Hospice patients' reflections on the meaning of life and death. Counseling Psychology Quarterly, 31(2), 162-185.

Publisher's Note Springer Nature remains neutral with regard to jurisdictional claims in published maps and institutional affiliations. 